\title{
Exploring registered nurses' attitudes towards post graduate education in Australia-instrument development
}

\author{
Linda C. Ng, Anthony G. Tuckett, Stephanie K. Fox-Young, Victoria J. Kain \\ School of Nursing and Midwifery, The University of Queensland, Queensland, Australia.
}

Correspondence: Linda Ng. Address: School of Nursing and Midwifery, The University of Queensland, U7/47-49 Newcomen Street, Brisbane, Queensland, Australia. Email: Linda.Ng@uqconnect.edu.au

Received: J une 14, 2013

DOI : $10.5430 /$ jnep.v4n3p20
Accepted: August 20, 2013

URL: http://dx.doi.org/10.5430/jnep.v4n3p20

\section{Abstract}

Background: Nursing education is designed to prepare competent nurses to meet the current and future health care needs of society. Changes to nursing education, especially at post graduate level, will therefore likely be influenced by the on-going developments in healthcare and socio-economic factors.

Objective: The primary objective of this study is to develop and validate an instrument that explores the beliefs of Registered Nurses about Postgraduate education in the context of specialist nursing practice in Australia (specialty education).

Methods: The Nurses’ Attitudes Towards Post Graduate Education (NATPGE) instrument was sent to an expert panel to undertake judgment-quantification (content validity testing). Content Validity Index (CVI) based on expert ratings of relevance was used as a method of quantifying content validity for the NATPGE instrument. A convenience sample of 25 registered nurses was selected from four major Queensland tertiary hospitals to assess the face validity of the instrument. A random sample of 100 registered nurses from the Nurses and Midwives e-Cohort Study (NMeS) were invited to participate in test-retest procedures to assess the reliability of NATPGE overtime. The instrument was administered at two different time points, 3 weeks apart, under similar conditions.

Results: Content and face validity was assessed using descriptive statistics. For the test-retest reliability, data were analysed on an item by item basis to calculate the intra-rater reliability using the weighted kappa $\left(\mathrm{k}_{\mathrm{w}}\right)$ statistic. The NATPGE instrument attained moderate test-retest reliability. $80 \%$ of the items on the instrument reached a fair to moderate agreement between the test and retest.

Conclusions: There is a need for development of a robust psychometric instrument to explore Registered Nurses' Attitudes Towards Post Graduate Education (NATPGE) and this research is the first step in addressing this need.

\section{Key words}

Instrument development, Postgraduate education, Registered nurses

\section{I ntroduction}

The nursing profession responds to changes in health care needs by exploring new methods for providing care, by changing educational emphases, and by establishing practice standards in new areas ${ }^{[1]}$. Changes to nursing education, 
especially at Postgraduate level, will therefore likely be influenced by the on-going developments in healthcare and socio-economic factors ${ }^{[2,3]}$.

According to Larson ${ }^{[4]}$, the one central function of professions (or their counterparts) in most advanced societies is that of "organising the acquisition and certification of expertise in broad functional areas, on the basis of formal educational qualifications held by individuals". The transfer of Australian specialty Postgraduate nursing education from hospitals to the tertiary (higher education) sector took place in the late-90s ${ }^{[5]}$. Postgraduate education in nursing has continued to grow over the years but the benefits to students, employers, patients and overall impact on practice remain unclear ${ }^{[2,6,7]}$.

A literature search was undertaken to provide an overview of issues relating to Postgraduate education for specialty practice, in particular on the experience of Postgraduate education on registered nurses' attitudes towards specialty practice; the perception of facilitators and challenges to Postgraduate education for specialisation; and on the Registered Nurses' intention to remain in nursing. Computerised databases: CINAHL, PubMed, Medline, EMBASE, Scopus, ERIC, BERA, Cochrane and PsycINFO were used to identify journal articles, books and book chapters using key search terms in various combinations. The search was also broadened to include "grey" literature as well as using internet search engines, for example Google Scholar, to identify key words in reports. This was followed by a literature search of relevant references in the already extracted studies, which were then retrieved and included in the literature review if relevant. The primary themes deduced from a guiding framework and additional themes identified from the review were used to inform the content of an instrument to explore registered nurses' attitudes towards Postgraduate education and speciality practice. A full description of the literature review methods is reported elsewhere. The primary themes deduced from the guiding framework and additional themes identified from the review are to inform the content of an instrument to explore registered nurses' attitudes towards Postgraduate education and speciality practice. The review also identifies the gaps in research that need to be addressed in order to develop a knowledgebase about registered nurses' attitudes towards Postgraduate education for specialty practice, and the facilitators and challenges they encounter in accessing it.

Whilst the outcome from the literature review is yet to be reported, a range of issues affecting registered nurses' attitudes to Postgraduate education for specialty practice emerged, in particular around their own experiences but also the attitudes of others. In a study that explores a Postgraduate critical care course, students reported a change in attitudes to nursing, stating that they have a 'much wider view of the whole picture' in critical care nursing ${ }^{[8]}$. Pelletier et al. ${ }^{[9]}$ also reported that nurses felt that Postgraduate education expanded their outlook on nursing.

Additionally, the literature provided some insight into the facilitators and challenges faced by registered nurses in undertaking Postgraduate education as well as the benefits they perceive as accruing from such study. In the case of facilitators and challenges, typically facilitators included career advancement and increased credibility while challenges were more wide-ranging including difficulties with work-study life balance and family relationships.

\section{Objective}

This main objective of this research is the development and validation of an instrument to explore the attitudes of registered nurses about Postgraduate education in the context of specialist nursing practice in Australia (specialty education).

\section{Methods}

Survey method was identified as the most appropriate to answer the overarching research questions for this study. Survey methods allow researchers to collect a large amount of data in a relatively short time ${ }^{[10]}$; the anonymity of survey responses also gives greater assurance of confidentiality ${ }^{[10]}$ and it is less expensive than other data collection methods ${ }^{[10,11]}$. This approach will produce objective, quantifiable data that can be replicated. It is true however, that the method can yield limited data by not providing in-depth information about participants' feelings toward the subject under 
study ${ }^{[12]}$. On the other hand, a survey is most likely to access a greater variety of opinions/ attitudes among registered nurses, particularly when research time is limited ${ }^{[13]}$.

\section{I nstrument development}

The first step in the development and design of the Nurses' Attitudes Towards Post Graduate Education (NATPGE) questionnaire was to organise the themes identified in the literature to inform the content of the instrument. Quantitative survey methods were chosen for this research because the development of the instrument would enable baseline data to be collected on the effect of post graduate education on a range of attitudes, knowledge and behaviour. Survey methods have a long history, are well defined, and have precise procedures which when followed closely, yield valid and easily interpretable data ${ }^{[10,12,14]}$.

The content of domain identification and item generalisation differ as a function of whether the instrument is a cognitive or affective measure ${ }^{[15]}$. Instrument development, in which items are refined and organised in an appropriate sequence and format, is the same for both cognitive and affective measures ${ }^{[15,16]}$. Therefore, the domain identification for our instrument was accomplished through literature review ${ }^{[15,16]}$.

The majority of items for the instrument developed for this study were derived from the themes previously identified in a study on new nursing graduates in New Zealand ${ }^{[17]}$. McDonald et al. ${ }^{[17]}$ conducted a cross sectional survey on a group of 51 new nursing graduates undertaking Postgraduate education within a Nursing Entry to Practice (NETP) program. According to McDonald et al. ${ }^{[17]}$, in New Zealand; various district health boards offer Postgraduate courses within their NETP programs that are designed to support the graduate in developing the knowledge and skills required to progress from a new graduate registered nurse to a competent registered nurse. At the same time, McDonald et al. ${ }^{[17]}$ notes, graduates are expected to perform the role of a beginning practitioner as well as embark on post graduate education during their first year of practice. McDonald et al.'s ${ }^{[17]}$ purpose was to explore the graduate nurses' experience of Postgraduate education within a NETP program. Amongst other aims of the study, they also explored the perceived benefits and challenges of Postgraduate education within this program. Several of the themes identified by McDonald et al. ${ }^{[17]}$ and our literature review represented either facilitators or challenges to Postgraduate education and these became the basis of items in that area on the instrument. Themes derived from McDonald et al. ${ }^{[17]}$ and our literature review were converted to Likert scale questions for use in the NATPGE questionnaire. The decision to design the NATPGE instrument, instead of relying on McDonald et al.'s ${ }^{[17]}$ study was pragmatic. McDonald et al.'s ${ }^{[17]}$ research was open design (interviews) and therefore, more time would be required to explore the themes from interviews. Our secondary purpose was to encourage a greater response rate in a short period of time by providing an easier and quicker experience for the respondents ${ }^{[18]}$. The NATPGE instrument enables data to be collected in a standardised way so that the data are internally consistent and coherent for analysis $^{[18,19]}$.

A Likert scale was used as the psychometric response to provide a measure of extremity and direction ${ }^{[10]}$. The response scale was coded accordingly: Strongly Agree $=1$, Agree $=2$, Disagree $=3$, Strongly disagree $=4$, and Unsure $($ Neutral) $=$ 5. Usually, in a continuum variables scale, the "Unsure" response is coded to the middle and assigned a score of "3". However, for the NATPGE instrument, the "Unsure" response was situated to the far right of the scale making it less conspicuous in an effort to discourage participants from routinely selecting the "Unsure" response ${ }^{[20]}$.

Internet-based surveys provide an attractive alternative to postal and telephone surveys of health professionals. It is worth noting that we relied on the Nurses and Midwives e-Cohort Study (NMeS) for sampling participation. The NMeS is a longitudinal web-based study of 7,604 nurses and midwives in three countries: Australia, New Zealand and the United Kingdom. The full detail of the NMeS is described in Turner et al. ${ }^{[21]}$ and Huntington et al. ${ }^{[22]}$ and the profile of the cohort has been reported. Internet-based surveys raise important technical and methodological issues which need to be carefully considered before widespread implementation ${ }^{[10,13,20]}$. Our approach encountered some of these as follows: the site 
crashed on the day the survey was open; some participants were not able to access the survey on the retest despite completing the survey in the initial test attempt and a number of the emails addresses of participants were not updated.

For the purpose of this research, it was important to gain a representative sample of registered nurses across geographically diverse States and Territories of Australia, so an online survey format was deemed to be the most suitable. We describe the sample later.

\section{Instrument validation: Content validity}

Content validation is the rigorous assessment consisting of a two-stage process: (i) instrument development and (ii) judgment-quantification and is considered fundamental to virtually all instrument design ${ }^{[10,16,19]}$. Although Lynn ${ }^{[16]}$ recommended a minimum of three in a panel of experts, others have suggested a range of two to 20 experts ${ }^{[23,24]}$.

For the judgement-quantification aspect of this study, four panel members were selected for the different expertise each could bring to the critique of the items. The four expert domains were: expertise in the clinical area, expertise in the development of psychometric scales and expertise in the development as well as in the analysis of an instrument. Members of the Expert Panel included a nurse academic and an expert in the content area from New Zealand, two nurse academics; experts in the content area and development and analysis of an instrument and finally, an expert in development of psychometric scales.

Members of the Expert Panel were given instructions, the NATPGE instrument and a rating form. They were asked to assess the items for clarity, logic of fit, and domain coverage. The most widely used method of quantifying content validity for multi-item scales is the content validity index (CVI) based on expert ratings of relevance ${ }^{[25]}$. A cut off of $75 \%$ (i.e. $75 \%$ of expert panel) or greater was selected to ensure strong and broad support for the retention of a question. All questions scored highly on the CVI and the only comments from the expert panel resulted in some minor changes to the wording of some items for better clarity and simplicity (see Table 1). Peat, Mellis, Williams and Xuan ${ }^{[26]}$ suggest re-wording or re-scaling any questions as recommended by the panel to improve internal validity of an instrument as well as to ensure that the replies can be interpreted in terms of the information that is required. The expert panel was agreeable that the items were arranged in a positively and negatively worded sequence, which was intentional as to prevent response bias ${ }^{[20]}$.

\section{Instrument development: Face validity}

Face validity is directly related to the participants'/subjects' acceptance of the text ${ }^{[27]}$. The measurement instrument must be understandable and perceived as relevant by the participants/ subjects to ensure their cooperation and motivation ${ }^{[28]}$.

A cohort of 25 registered nurses was selected by a convenience sampling approach (i.e., was readily available) and invited to assess the instrument as amended following the Expert Panel feedback. Relying on this group ensured that the population for whom the NATPGE instrument had been developed was captured and that the items in the NATPGE instrument were salient for that group. This group of registered nurses was asked to assess issues such as phrasing and terminology and recommend other important or salient terms for inclusion ${ }^{[29]}$.

Completed data were collected from all 25 registered nurse volunteers, who were mainly colleagues and clinicians in the hospitals, in which the principal researcher works. The registered nurses were asked for feedback to identify ambiguities and difficult questions. They were also asked to record the time taken to complete the instrument. According to Peat et al. ${ }^{[26]}$, all unnecessary, difficult or ambiguous questions are to be discarded to improve internal validity of an instrument. Most of the respondents felt that the instrument was clear, simple and unambiguous. However, four (4) respondents were confused as to the term "specialty education" and commented that the phrase was ambiguous and unclear. An amendment was made to the instrument by adding the definition of "specialty" to the heading of the instrument: "Specialty education refers to education that focused on a particular field of nursing practice (e.g. ICU, ED)”. 
Table 1. Feedback from Expert Panel

Questions
4.1 = A Registered Nurse needs to have a Post Graduate
qualification related to their specialty practice in order to be
called a specialist nurse

4.2 = A Registered Nurse needs to have experience in a specialty clinical setting before they can be called a specialist nurse

4.3 = A Registered Nurse needs to have both a Post Graduate education qualification relevant to their specialty practice and experience in the specialty clinical setting before they can be called a specialist nurse

4.4 = Post Graduate education is useful for nurses in specialty practice

4.5 = Post Graduate education in a specialty area enhances nurses' careers

4.6 = Undertaking Post Graduate education whilst working in a shift environment is stressful

4.7 = Post Graduate education in a clinical area increases nurses' confidence

$4.8=$ It is difficult to balance work, study and family whilst undertaking Post Graduate education

4.9 = Post Graduate education is mainly for single people, it is not appropriate for people with family responsibilities

$4.10=$ Post Graduate education in a clinical setting improves nurses' knowledge

$4.11=$ There is no difference in practice between a Registered Nurse with a Post Graduate specialty practice qualification and a Registered Nurse without a Post Graduate qualification

4.12 = A Registered Nurse when undertaking Post Graduate education needs support from their employer

4.13 = A Registered Nurse with Post Graduate specialty practice education experiences increased job satisfaction 4.14 = Post Graduate education in a clinical specialty improves nurses' skills

4.15 $=$ The cost of Post Graduate education is too high

4.16 = Post Graduate education improves specialist nurses' critical thinking

\section{Comments from expert panel}

Feedback from expert panel:

Very relevant

Very simple

Very clear

Feedback from expert panel:

Very relevant

Very simple

Very clear

Suggestion from one of the expert panel members: Maybe emphasise the word BOTH (capitals, or bold)?

Feedback from expert panel:

Very relevant

Very simple

Very clear

Feedback from expert panel:

Very relevant

Very simple

Very clear

Suggestion from one of the expert panel members:

"Whilst also working in a shift environment" could be clearer

Feedback from expert panel:

Very relevant

Very simple

Very clear

Suggestion from one of the expert panel members:

Not everybody has a family. Maybe "work-life balance" is better

Suggestion from one of the expert panel members:

Single people can have children too, single mothers for example..

Suggestion from one of the expert panel members:

Nurses obtain a better understanding of their field from a post graduate education in a clinical setting

Suggestion from one of the expert panel members:

An RN with a post graduate specialty practice qualification is equivalent to an RN without a post graduate qualification for practical purposes Suggestion from one of the expert panel members:

Employer support is necessary for RN post graduate study to be successful

Suggestion from one of the expert panel members:

Post graduate specialty education leads to increased job satisfaction

Suggestion from one of the expert panel members:

Specialty post graduate education improves nurses' clinical skills

Feedback from expert panel:

Very relevant

Very simple

Very clear

Feedback from expert panel:

Very relevant

Very simple

Very clear 


\section{Sample for test re-test reliability testing and data collection}

The sample was drawn from the Nurses and Midwives e-Cohort Study (NMeS) which was representative of the registered nurses’ population in Australia ${ }^{[21,22]}$ with participants in all States and Territories of the country. Potential research participants were those who consented at the time of enrolment in the NMeS to be contacted for other research. The ethical approaches for the larger survey were rigorous and are described in detail elsewhere ${ }^{[21,22]}$.

Reliability is the consistency of a set of measurements or of a measuring instrument ${ }^{[12]}$ and reliability does not imply validity $^{[12,20]}$. It was important that the sample for the pilot be representative of the target study population ${ }^{[30]}$ as well as large enough to provide useful information ${ }^{[30,31]}$. However, we recognise there is no consensus on the size of the sample that is needed for reliability studies ${ }^{[32]}$.

A random sample of approximately 100 registered nurses selected from the NMeS by computer program was invited to participate in a test-retest pilot as part of the process of assessing the reliability of the online NATPGE. To ensure maximum response rates, all information sent to the participants was concise and succinct, and all participants were informed in advance of their commitment i.e. the instrument would need to be completed twice, the second time 3 weeks after the first.

To gauge test-retest reliability, the instrument was administered at two different time points in time 3-4 weeks apart, under similar conditions ${ }^{[10]}$. This time period is to prevent the "carryover effect" of respondents recalling their previous responses, particularly if the interval between test and retest is short ${ }^{[33]}$. This kind of reliability testing is used to assess the consistency of responses to a questionnaire across time ${ }^{[20]}$.

\section{Data collection and analysis}

Data were collected and analysed using Stata 12 (StataCorp. 2011, TX: StataCorp LP.). All items were analysed on an item by item basis to calculate the reliability agreement. For appraising reliability, a useful measure of inter-rater reliability or intra-rater agreement is provided by weighted kappa ${ }^{[34,35]}$. When data to be analysed are ordinal data, the kappa statistic has been advocated as one of the preferred methods for the analysis of agreement data ${ }^{\text {[36] }}$. The reference values for the strength of agreement we used were in accordance with Altman ${ }^{[37]}$ who considers $<0.2$ as poor agreement, $0.21-0.40$ as fair, $0.41-0.60$ as moderate, $0.61-0.80$ as good and $0.81-1.00$ as a very good agreement.

\section{Ethical consideration}

The NATPGE pilot study was approved by The University of Queensland Behavioural and Social Sciences Ethical Committee (2011000884). The NMeS was also approved by the Behavioural and Social Sciences Ethical Review Committee of The University of Queensland.

\section{Results}

\section{I- Content validity index}

Overall, the expert panel ranked the NATPGE, using the CVI, as a realistic tool that would be useful for evaluating registered nurses' attitudes towards Postgraduate education. The comments received from the expert panel resulted in some minor changes to the wording of some items for better clarity and simplicity. No particular concerns were raised about any of the items by the expert panel. The expert panel was agreeable that the items were arranged in a positively and negatively worded sequence, which was intentional as to prevent response bias.

\section{I - Test retest}

The test-retest reliability in registered nurses' attitudes towards Postgraduate education during the three week period indicates a level of instability in attitudes. The sample consisted of registered nurses with at least two years' post- 
registration experience. Demographic data indicated that the sample consisted of $66.8 \%(n=24)$ registered nurses with more than 15 years' experience in nursing and $69.3 \%(n=25)$ between the ages of 41 years to 60 years old. A post graduate qualification was held by $63.9 \%(n=23)$ of the respondents compared to $22.2 \%(n=8)$ with hospital qualification. Respondents' gender was not part of the demographic data we collected.

\section{Discussion}

In this research, there were 46 (46\%) respondents in the test S1 and 36 (78.3\%) participated in the retest S2. The results from the NATPGE instrument display a moderate agreement between the test and retest (see Figure 1).

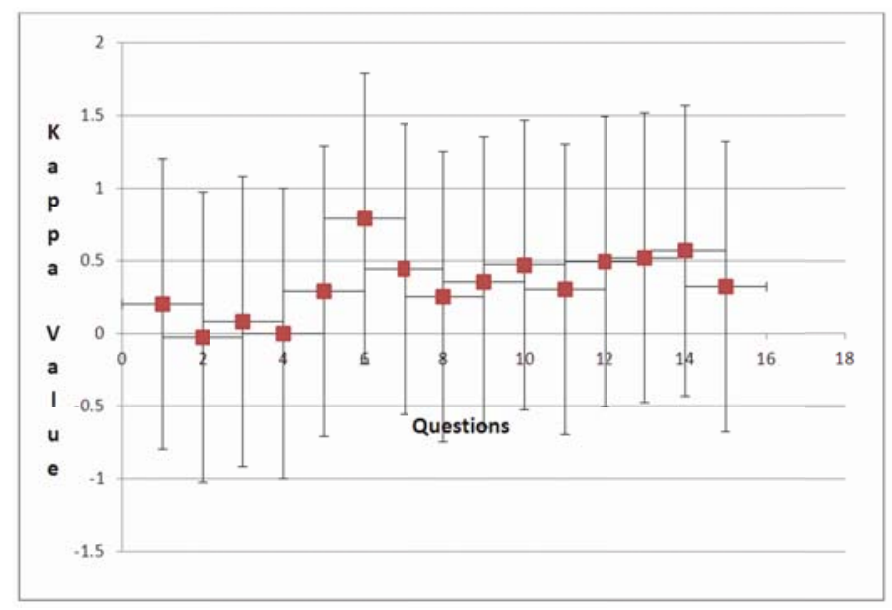

Figure 1. Kappa Values between Test (S1) and Retest (S2)

Only two items, concerning the requirement of Postgraduate education qualification and experience before a registered nurse is considered as a specialty nurse; and the usefulness of Postgraduate qualification to registered nurses, had low test-retest reliability (see Table 2).

There are no plausible hypotheses that a group consisting of a majority of middle age registered nurses should be more inconsistent in their attitudes than any other group. Other potential explanations for this variation include changes in the context or constructs being measured; an inadequate or excess interval in the test-retest timeframe; and an inadequate sample.

As far as we can determine, there was no significant changes in the context in which the survey was administered and we assume that there were no substantial changes in the construct being measured in the test-retest reliability pilot. We know that if we measure the same thing twice the correlation between the two observations will depend in part on how much time elapses between the two measurement occasions. The shorter the time gap, the higher the correlation; the longer the time gap, the lower the correlation ${ }^{[20]}$. This is because the two observations are related over time - the closer in time we test, the more similar the factors that contribute to error. From our results, some variables did change between the test and retest measurements. We therefore hypothesise that this moderate rather than strong agreement between the test and retest is not because there is anything wrong with our measurement method- but has occurred because people's moods have changed or the experience of taking the test itself has changed individuals' true score as observed by Davidshofer and Murphy ${ }^{\text {[38] }}$.

While the small sample size ( $\mathrm{n}=36$ ) may have increased the risk of a lack of statistical representation of registered nurses and of producing fully conclusive results, Currier ${ }^{[39]}$ states that when studying relationships (correlation), at least 30 subjects should be gathered. Although the test-retest sample here was small $(\mathrm{n}=36)$, it is an exploratory research. Exploratory research is not intended to provide conclusive evidence, but to assist us to have a better understanding of the 
problem ${ }^{[40]}$. Nor does it aim to provide the final and conclusive answers to the research questions, but merely to explore the research topic with varying levels of depth ${ }^{[41]}$ or to tackle new problems on which little or no previous research has been done ${ }^{[42]}$. This study is the initial phase of a larger investigation and forms the basis for more conclusive research. It has validated and assessed the reliability of the research instrument and helped us to fine-tune the research design, sampling methodology and data collection method ${ }^{[43]}$.

Table 2. Kappa Weighted Values between Test and Retest Repeated Measures

\begin{tabular}{|c|c|c|}
\hline Questions & Kappa value & 95\% Confidence Interval \\
\hline $\begin{array}{l}\text { A Registered Nurse needs to have a Post Graduate qualification } \\
\text { related to their specialty practice in order to be recognised by the } \\
\text { profession as a specialist nurse }\end{array}$ & 0.20 & $0.51,-0.11$ \\
\hline $\begin{array}{l}\text { A Registered Nurse needs to have experience in a specialty clinical } \\
\text { setting before they can be called a specialist nurse }\end{array}$ & -0.03 & $0.36,-0.36$ \\
\hline $\begin{array}{l}\text { A Registered Nurse needs to have BOTH a Post Graduate } \\
\text { qualification relevant to their specialty practice and experience in } \\
\text { the specialty clinical setting before they can be called a specialist } \\
\text { nurse }\end{array}$ & 0.08 & $0.37,-0.20$ \\
\hline $\begin{array}{l}\text { Specialty Post Graduate education is useful for nurses in specialty } \\
\text { practice }\end{array}$ & 0.00 & $0.00,0.00$ \\
\hline Post Graduate education in a specialty area enhances nurses’ careers & 0.29 & $0.56,0.03$ \\
\hline $\begin{array}{l}\text { Undertaking Post Graduate education whilst also working in a shift } \\
\text { environment is stressful }\end{array}$ & 0.79 & $1.10,0.47$ \\
\hline $\begin{array}{l}\text { Specialty Post Graduate education increases nurses’ confidence in } \\
\text { clinical decision making }\end{array}$ & 0.44 & $0.72,0.16$ \\
\hline $\begin{array}{l}\text { It is difficult to balance work, study and social life whilst } \\
\text { undertaking Post Graduate education }\end{array}$ & 0.25 & $0.47,0.03$ \\
\hline Specialty Post graduate education improves nurses knowledge & 0.35 & $0.62,0.08$ \\
\hline $\begin{array}{l}\text { There is NO DIFFERENCE in clinical practice between a } \\
\text { Registered Nurse with a Specialty Post Graduate qualification and a } \\
\text { Registered Nurse without a Specialty Post Graduate qualification }\end{array}$ & 0.47 & $0.73,0.22$ \\
\hline $\begin{array}{l}\text { Employer support is necessary for post graduate study to be } \\
\text { successful }\end{array}$ & 0.30 & $0.56,0.03$ \\
\hline $\begin{array}{l}\text { A Registered Nurse with Specialty Post Graduate education } \\
\text { experiences increased job satisfaction }\end{array}$ & 0.49 & $0.72,0.16$ \\
\hline Specialty post graduate education improves nurses' clinical skills & 0.52 & $0.79,0.25$ \\
\hline The cost of Post Graduate education is too high & 0.57 & $0.85,0.29$ \\
\hline $\begin{array}{l}\text { Specialty Post Graduate education improves specialist nurses' } \\
\text { critical thinking }\end{array}$ & 0.32 & $0.61,0.03$ \\
\hline
\end{tabular}

\section{Conclusion}

The present research indicates good content and face validity and whilst the test-retest reliability overall was fair to moderate, several individual questions did have poor kappa values. As such, we plan to refine the instrument, before its validation in a larger sample. To ensure the usefulness of future research within this particular field, further development work to ensure a more reliable and valid tool will be undertaken in subsequent phases of the research.

\section{Acknowledgement}

We would like to acknowledge the contribution of Dr Kristen Gibbons, Statistician of Mater Medical Research Institute, Brisbane.

\section{References}

[1] Morris LL, Pfeifer PB, Catalano R, Fortney R, Hilton E, McLaughlin J, et al. Designing a comprehensive model for critical care orientation. Critical Care Nurse. 2007; 27(6): 37-61. 
[2] Gijbels H, O’Connell R, Dalton-O’Connor C, O’Donovan M. A systematic review evaluating the impact of post-registration nursing and midwifery education on practice. Nurse Education in Practice. 2010; 10: 64-9. PMid:19395313 http://dx.doi.org/10.1016/j.nepr.2009.03.011

[3] Heller B, Oros M, Durney-Crowley J. The future of nursing education: Ten trends to watch. http://wwwnlnorg/nlnjournal/infotrendshtm. 2007. Accessed: $10^{\text {th }}$ Dec 2012

[4] Larson MS. In the matter of experts and professionals, or how impossible it is to leave nothing unsaid. In The Formation of Professions: Knowledge, State and Strategy (Torstendahl R. \& Burrage, M eds) pp 24-50, London: Sage; 1990.

[5] Chaboyer W, Dunn S, Najman J. Developing specialty knowledge: The case of Australian critical care nursing. Intensive and Critical Care Nursing. 2000; 16: 13-7. PMid:10790711 http://dx.doi.org/10.1054/iccn.2000.1474

[6] Griscti O, Jacono J. Effectiveness of continuing education programmes in nursing: Literature review. Journal of Advanced Nursing. 2006; 55(4): 449-56. PMid:16866840 http://dx.doi.org/10.1111/j.1365-2648.2006.03940.x

[7] Pelletier D, Donoghue J, Duffield C. Understanding the nursing workforce: A longitudinal study of Australian nurses six years after graduate study. Australian Journal of Advanced Nursing. 2005; 23(1): 37-43. PMid:16496816

[8] Armstrong DJ, Adam J. The impact of a postgraduate critical care course on nursing practice. Nurse Education in Practice. 2002; 2: 169-75. PMid:19036294 http://dx.doi.org/10.1054/nepr.2002.0066

[9] Pelletier D, Donoghue J, Duffield C, Adams A, Brown D. Why undertake higher degrees in nursing? Journal of Nursing Education. 1998; 97(9): 422-4.

[10] Dillman DA. Mail and internet surveys: The tailored design (2nd ed.). New York, NY: John Wiley \& Sons; 2000.

[11] Shaughnessy JJ, Zechmeister EB, Zechmeister JS. Research methods in psychology (pp 143-192) (7th ed.): McGraw-Hill Higher Education; 2006.

[12] Polit D, Beck C. Essentials of nursing care: Methods, appraisal and utilization (7th ed.). Philadelphia: Lippincott Williams and Wilkins; 2010.

[13] Nie N, Hillygus S, Erbring L. Internet use, interpersonal relations and sociability: Findings from a detailed time diary study. B Wellman (Ed), The internet in everyday life (pp 215-243). London: Blackwell Publishers; 2002.

[14] Baker TL. Doing social research. New York: McGraw-Hill Inc.; 1994.

[15] Grant J, Davis L. Selection and use of content experts for instrument development. Research in Nursing and Health. 1997; 20: 262-74

[16] Lynn M. Determination and quantification of content validity. Nursing Research. 1986; 35: 383-5.

[17] McDonald S, Willis G, Fourie W, Hedgecock B. Graduate nurses' experience of post graduate education within a nursing entry to a practice programme. Journal of Nursing Management. 2009; 25(3): 17-26.

[18] Kumar R. Research Methodology. London: Sage Publications; 1996.

[19] Cohen L, Marion L. Research Methods in Education. London: Groom Helm Ltd; 1980.

[20] De Vaus D. Surveys in Social Research (5th ed.). Sort SI, editor. Sydney, Australia: Allen \& Unwin; 2002.

[21] Turner C, Bain C, Schluter P, Yorkston E, Bogossian F, McClure R, et al. Cohort profile: The Nurses and Midwives e-Cohort Study: A novel electronic longitudinal study. Int J Epidemiol. 2008:1-8.

[22] Huntington A, Gilmour J, Schluter P, Tuckett A, Bogossian F, Turner C. The internet as a research site: Establishment of a web-based longudinal study of nursing and midwifery workforce in three countries. Journal of Advanced Nursing: Research Methodology. 2009: 1309-17.

[23] Gable R, Wolf J. Instrument development in the affective domain: Measuring attitudes and values in corporate and school settings (6th ed.). Boston: Kluwer Academic; 1993.

[24] Waltz CF, Strickland OL, Lenz ER. Measurement in nursing and health research (4th ed.). New York: Springer Publisher; 2010.

[25] Polit D, Beck C, Owens S. Is the CVI an acceptable indicator of content validity? Appraisals and recommendations. Research in Nursing and Health. 2007; 30: 459-67. PMid:17654487 http://dx.doi.org/10.1002/nur.20199

[26] Peat J, Mellis C, Williams K, Xuan W. Health Science Research: A Handbook of Quantitative Methods. London: Sage; 2002.

[27] Polit D, Beck C, Hungler B. Essentials of nursing research: Methods, appraisal and utilization. 5th ed. Philadelphia: Lippincott Williams and Wilkins; 2001.

[28] Gould A. The issue of measurement validity in health-care research. British Journal of Therapy and Rehabilitation. 1994; 1: 99-108.

[29] Downing SM, Haladyna TM. Validity threats: overcoming interference with proposed interpretations of assessment data. Med Educ. 2004; 38: 327-33. http://dx.doi.org/10.1046/j.1365-2923.2004.01777.x

[30] Van Teijlingen ER, Rennie AM, Hundley V, Graham W. The importance of conducting and reporting pilot studies: The example of the Scottish Births Survey. Journal of Advanced Nursing. 2001; 34: 289-95. http://dx.doi.org/10.1046/j.1365-2648.2001.01757.x

[31] Thabane LJ, Ma J, Chu R, Cheng J, Ismaila A, Rios LP, et al. A tutorialon pilot studies: The what, why and how. BMC Medical Research Methodology. 2010; 10(1). 
[32] Charter RA. Study samples are too small to produce sufficiently precise reliability coefficients. The Journal of General Psychology. 2003; 130(2): 117-29. PMid:12773016http://dx.doi.org/10.1080/00221300309601280

[33] Howell D. Statistical methods for psychology. 7th ed. Belmont, CA: Thomson Wadsworth; 2010.

[34] Jakobsson U. Statistical presentation and analysis of ordinal data in nursing research. Scand J Caring. 2004; 18: 437-40. PMid:15598252http://dx.doi.org/10.1111/j.1471-6712.2004.00305.x

[35] Jakobsson U, Westergren A. Statistical methods for assessing agreement for ordinal data. Scand J Caring. 2005 ; $19: 427-31$. PMid:16324069 http://dx.doi.org/10.1111/j.1471-6712.2005.00368.x

[36] Viera A, Garrett J. Understanding interobserver agreement: The Kappa statistics. Family Medicine. 2005; 37(5): 360-3. PMid:15883903

[37] Altman DG. Practical statistics for medical research. Padstow,Cornwall1991.

[38] Davidshofer K, Murphy C. Psychological testing : principles and applications (6th ed. ed.). Upper Saddle River, N.J: Pearson/Prentice Hall; 2005.

[39] Currier DP. Elements of research in physical therapy (2nd ed.). Baltimore: Williams and Wilkins; 1984.

[40] Lambin J, J. Market-Driven Management: Strategic \& Operational Marketing: Palgrave; 2000.

[41] Bell J. Doing Your Research Project: A Guide for First Time Researchers in Education, Health and Social Science, Fifth Edition2010.

[42] Brown RB. Doing Your Dissertation in Business and Management: The Reality of Research and Writing: Sage Publications; 2006. [43] Singh K. Quantitative Social Research Methods: SAGE Publications; 2007. 